\title{
Associations between parenting styles and nutrition knowledge and 2-5-year-old children's fruit, vegetable and non-core food consumption
}

\author{
Jacqueline Peters ${ }^{1}$, James Dollman ${ }^{1}$, John Petkov ${ }^{2}$ and Natalie Parletta ${ }^{1, *}$ \\ ${ }^{1}$ School of Health Sciences, Sansom Institute for Health Research, City East Campus, University of South Australia, \\ Frome Road, GPO Box 2471, Adelaide, SA 5001, Australia: ${ }^{2}$ Health and Use of Time Group, Sansom Institute \\ for Health Research, University of South Australia, Adelaide, SA, Australia
}

Submitted 21 November 2011: Final revision received 30 August 2012: Accepted 14 September 2012: First published online 22 October 2012

\begin{abstract}
Objective: During the early years, parents have a major influence on children's diets and developing food choices. We investigated parenting styles as predictors of 2-5-year-old children's diets and whether general nutrition knowledge (GNK) mediated these influences.

Design: Cross-sectional research. Questionnaires measured demographic and lifestyle variables, family environment, parenting styles and feeding practices, child diet and GNK. Regression models tested GNK as a mediator of relationships between parenting variables and child diet (fruit/vegetable and non-core food consumption), controlling for confounders and family environment.

Setting: Questionnaires were completed by main caregivers at home.

Subjects: Parents of children aged $2-5$ years ( $n$ 269).

Results: Higher child fruit/vegetable consumption was associated with lower overreactive parenting and restriction, higher authoritative parenting and dining together as a family; with lax parenting approaching statistical significance $(P=0 \cdot 083)$ and $19 \%$ of variance explained by the model. GNK was not a significant predictor. Conversely, non-core food consumption was associated with higher over-reactive and lax parenting as well as child age, increased takeaway food consumption and higher television viewing; GNK had a small effect $(P=0.043)$ and $28 \%$ of variance was explained by the model. GNK was a significant mediator only for authoritative parenting on non-core food (effect $=-0 \cdot 005$ ).

Conclusions: These findings highlight that young children's diets may be improved by interventions targeting a range of positive and supportive parenting practices in conjunction with nutrition knowledge education for parents of young children. Further insights will come from closer attention to the nature and role of restrictive feeding practices $v$. laxness and longitudinal research.
\end{abstract}

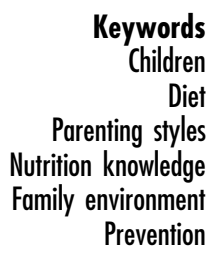

The 2007 Children's National Nutrition Survey reported that Australian children are consuming too few fruits and vegetables and excess non-core food ${ }^{(1)}$. Poor dietary habits and weight-related problems have gained widespread attention, with much of the research focusing on teen and/or adult age groups. However, research has found a higher prevalence of overweight and obesity in Australian 2-5-year-old children when compared internationally ${ }^{(2,3)}$. Furthermore, behaviours contributing to overweight and obesity are likely to track from an earlier age ${ }^{(4-6)}$, and habitualised behaviours are increasingly difficult to change ${ }^{(7)}$. Therefore, more research on the eating behaviours of children of pre-school age could assist in the prevention of child and adult overweight and obesity.

Established target areas in the early years include the home family environment, such as associations between increased television viewing and higher energy intake ${ }^{(8)}$. Further investigation into the role of parenting styles in children's diets could provide additional insights for targeting parents of younger children. Additionally, the influence of parent nutrition knowledge on the diets that parents provide for children may be a contributing factor. We identified previously in systematic reviews of qualitative and intervention research that general nutrition knowledge (GNK) has received little attention when investigating the influence of parenting styles on young children's diets ${ }^{(9,10)}$.

Controlling parent feeding practices, such as 'pressure to eat' and 'restriction', have tended to be associated with unhealthy diets, eating habits and/or weight ${ }^{(11-31)}$; however, not all research supports this. In one study, covert and overt control were associated with eating fruits and 
vegetables while less covert control was associated with higher snack food consumption ${ }^{(32)}$. Lack of associations between parental control and child autonomy (free access) and child overweight and/or BMI $Z$-score 33,34$)$ and increased consumption ${ }^{(13)}$ have been reported, as well as differences between maternal and paternal restriction $^{(35)}$ and findings that paternal restriction was associated with higher child $\mathrm{BMI}^{(34)}$. Other studies found that restrictive behaviours were bidirectional ${ }^{(19)}$; favourable child behavioural styles (non-depressive, low anxious and low overactive) combined with restrictive practices were related to decreased consumption of restricted (unhealthy) and increased consumption of healthy foods ${ }^{(36)}$; maternal feeding practices were found to be domain specific and differed between siblings depending on the child's weight ${ }^{(37)}$; and differences were found in levels of restriction throughout the day ${ }^{(17)}$. In the latter study, reduced consumption of restricted sugary foods was reported at breakfast and lunchtime and increased consumption in the afternoon when restrictions were reduced. Greater restrictions on these foods were associated with increased preference for them and results suggested increased consumption in the absence of parental control $^{(17)}$. In consideration of these studies, it is suggested that research on restrictive feeding practices in general is limited by inconsistencies in the operationalisation and measurement of restriction ${ }^{(9,38)}$.

Seven cross-sectional studies included parenting styles (authoritative, authoritarian and permissive) ${ }^{(30,33,34,39-42)}$. Consistent with authoritative parenting producing better developmental outcomes compared with the other styles, authoritative parenting has generally been associated with positive dietary or weight-related outcomes ${ }^{(41-45)}$ whereas negative associations have been found with authoritarian $^{(39-41)}$ and permissive ${ }^{(30,33,41,42)}$ parenting. Similar to findings from intervention ${ }^{(9)}$ and qualitative ${ }^{(10)}$ research, none of the observational studies identified here measured parenting styles and GNK together.

From studies that have measured child diet and/or BMI, only four measured parental $\mathrm{GNK}^{(43-46)}$. One study developed a healthy eating and exercise questionnaire to detect GNK differences between Latino (70.3\% correct) and black women $(70 \cdot 1 \%$ correct); however, as no differences were detected the authors made no further reference to maternal $\mathrm{GNK}^{(45)}$. Colavito and colleagues used the Diet Health Knowledge Survey (DHKS; twenty-six items) to evaluate relationships between household meal planners' GNK and parent/child fat and fibre intakes ${ }^{(43)}$. Results indicated that children of meal planners with more nutrition knowledge ate less fat at home; however, results did not reach significance for total fat or fibre intake. None the less these results support the notion of parental nutrition knowledge influencing child diet. Etelson et al. evaluated parents' knowledge of healthy eating, assessing differences between parents of normal weight ( $n$ 64) and overweight children $(n 23)^{(44)}$, using two multiple-choice questions: how much juice ( $8 \mathrm{oz}$ juice boxes) parents thought was healthy for their child to drink daily and how often they felt it was appropriate to eat at fast-food restaurants. Two-thirds of parents suggested that children should drink no more than two boxes of juice daily and $96 \%$ believed fast food should be limited to once weekly or less, with no significant difference between the groups ${ }^{(44)}$. More recently, selected questions from the DHKS were used to assess associations between parents' ( $n$ 447) diet-related knowledge and child BMI and fruit/ vegetable intakes, comparing parents of healthy and overweight children $^{(46)}$. No significant differences were reported between groups with most parents aware of the recommended fruit and vegetable servings. However, all children consumed less than one average serving of vegetables daily. Overall, $60 \%$ consumed two or more pieces of fruit daily although $75 \%$ of overweight children consumed fewer than two pieces daily. There were no relationships between parental GNK and child fruit and vegetable intake. However, the authors comment that parents of overweight children (BMI $\geq 95$ th percentile) were almost twice as likely to disagree with the statement 'what you eat makes a difference in your chances of getting disease ${ }^{,(46)}$, thereby suggesting that diet-related knowledge and attitudes are not the same in all groups. Therefore, of the four studies to evaluate GNK only one found a relationship between parental GNK and child diet, although three out of four studies implied GNK to influence related outcomes.

Although two of the latter studies evaluated a parenting component, one ${ }^{(45)}$ looked at parental support and role modelling only and the other assessed parental attitudes towards childhood obesity with one question only ${ }^{(44)}$. It could be speculated that, although parental style and family environment may influence child diet, this influence could be mediated by parental knowledge of what constitutes a healthy diet. Therefore, in light of the dearth of studies combining parental and nutrition knowledge influences on child diet, the purpose of the present crosssectional study was to develop a survey to investigate factors associated with child fruit/vegetable and non-core food consumption, including demographic variables such as socio-economic status (SES), parental education and children's BMI, family environment (e.g. television viewing, dining together as a family), parenting styles and parental GNK. It was hypothesised that, controlling for family environment and covariates, parenting styles would predict the quality of children's diets and parent GNK would partially mediate these influences.

\section{Methodology}

\section{Recruitment}

South Australian parents were recruited during 2008-2009 via school newsletters, day-care centres, kindergartens, 
out-of-school-hours care, information pamphlets posted on hospital and university information boards, and email distribution lists. The information provided inclusion criteria, briefly outlined the study and offered a double movie pass in appreciation for time taken to complete questionnaires. Interested parents contacted the researcher via telephone or email and survey packages were posted containing information, instructions, the questionnaire and a reply paid envelope.

\section{Participants}

Two hundred and sixty-nine parents were recruited. Eligible parents had a child aged 2-5 years and needed to read English to complete the questionnaires. The study included children of all weights, diets and special needs. Emphasis was placed on obtaining responses from a cross-section of SES areas based on the Socio-Economic Index for Areas (SEIFA) according to postcodes organised by Australian Bureau of Statistics census data from 2004 (for income, education attainment and occupation; www.abs.gov.au), whereby ' 1 ' = most disadvantaged and ' 10 ' = least disadvantaged socio-economic areas.

Ethics approval was obtained from the University of South Australia Human Research Ethics Committee. Consent was implied by completion of the questionnaire. In an additional data collection drive, parents who completed the questionnaire signed consent forms so that we could contact them for focus group research.

\section{Power}

Twelve variables included in the current mediation analysis results in $52 \mathrm{df}$. Based on root-mean-square error of approximation $^{(47)}$, power was set at $80 \%$ with an $\alpha$ level of $0 \cdot 05$. To achieve this level of power 208 participants were needed. With the 269 participants recruited, the power achieved was $90 \%$.

\section{Measures}

The parent questionnaire measured demographic and lifestyle variables, family environment, parenting styles and feeding practices, child diet and GNK, as outlined below.

\section{Demographics/family environment}

Residential postcodes, cultural background, employment status, occupation, income and education levels of both parents were derived from the primary carer's responses. Questions about family environment included child's television viewing hours, number of hours in child care, how often the family ate together and number of takeaway meals per week.

\section{BMI and BMI Z-scores}

Parental reports of BMI are often used in evaluative surveys and are considered to be an acceptable substitute when actual measures are not available ${ }^{(48,49)}$. Parents provided children's height/weight details which were used to calculate BMI $\left(\mathrm{kg} / \mathrm{m}^{2}\right)$ and BMI $Z$-scores. Height and weight of both parents were self-reported and BMI was calculated.

\section{Children's diet quality}

The Children's Dietary Questionnaire (CDQ) was used to measure diet quality ${ }^{(50)}$. Four scores are derived from twenty-eight items measuring: (i) fruit/vegetable intake; (ii) fat from dairy; (iii) sweetened beverages; and (iv) non-core foods (high in fat/sugar). Reportedly, parental accounts of child diet and food frequency are accurate enough for use in dietary surveillance ${ }^{(51)}$. Reliability, internal consistency and validity were established in multiple samples of Australian children aged 4-16 years. The Fruit and Vegetable and Non-core Foods subscales demonstrate acceptable internal consistency (Cronbach's $\alpha=0.76$ and 0.62 , respectively) and item total correlations were greater than $0 \cdot 2^{(50)}$. The Fat from Dairy and the Sweetened Beverages subscales were not of interest in the present study.

\section{Parental feeding practices}

The Child Feeding Questionnaire (CFQ) is a thirty-oneitem self-report measure of parental perceptions and practices related to child feeding ${ }^{(52)}$. We used the three parental feeding subscales: Restriction (eight items); Pressure to Eat (four items); and Monitoring (three items). Internal consistency (Cronbach's $\alpha$ ) of the original scales ranges from 0.70 for pressure to eat to 0.92 for monitoring ${ }^{(52)}$. Although the sample age ranged from 5 to 11 years, the CFQ is designed for use with parents of children aged approximately $2-11$ years.

\section{Parenting styles}

The Parenting Scale (PS) is a thirty-item self-report measure of parental discipline strategies, validated on parents of children aged 18-48 months ${ }^{(53)}$, middle-school children ${ }^{(54)}$ and children with attention-deficit/hyperactivity dis$\operatorname{order}^{(55)}$. Values of $\alpha$ coefficients for individual factors are reported as 0.83 for Laxness, 0.82 for Over-reactivity, 0.63 for Verbosity and 0.84 for the total instrument; and test-retest correlations are reported as 0.83 for Laxness, $0 \cdot 82$ for Over-reactivity and 0.79 for Verbosity ${ }^{(53)}$.

The Parental Authority Questionnaire-Revised (PAQ-R) ${ }^{(56)}$ is a thirty-item modified version of Buri's Parental Authority Questionnaire (PAQ), designed to measure the extent to which parents' attitudes of parenting are consistent with Baumrind's parenting typologies: authoritativeness (allowing autonomy within clearly defined boundaries while displaying warmth and responsiveness), authoritarianism (highly directive, detached, unresponsive) and permissiveness (relatively non-controlling, few demands, no boundaries) ${ }^{(57)}$. It differs from the PS which measures dysfunctional parenting practices. Values of $\alpha$ coefficients are reported as 0.72 to 0.76 across the three subscales ${ }^{(56)}$. 
General nutrition knowledge

The General Nutrition Knowledge Questionnaire (GNKQ) ${ }^{(58)}$ is an Australian adaptation of the original GNKQ measuring dietary recommendations, sources of nutrients, choosing everyday foods and diet/disease relationships ${ }^{(59)}$. Overall internal and test-retest reliabilities for this forty-two-item questionnaire are reported as high (Cronbach's $\alpha=0.92$; $r=0 \cdot 87)$ and testing of the modified version reported it as a valid and reliable measure of GNK in a sub-sample of the Australian population ${ }^{(58)}$.

\section{Statistical analysis}

The study employed a cross-sectional research design. Statistical analyses were conducted using the statistical software package SPSS version 18.0 for Windows. Zeroorder correlations explored associations between potential confounders (demographic) and outcome variables (fruit/ vegetable and non-core food consumption). Demographic variables associated with the outcome variables were entered into regression models along with GNK, family environment, parenting and feeding style variables, and GNK was tested as a mediator between predictor and outcome variables. Bootstrapping was employed using 5000 samples for indirect effect confidence intervals set at $95 \%{ }^{(60)}$.

\section{Results}

\section{Descriptive}

Demographic characteristics are summarised in Table 1. A total of 269 parents (75\%) completed the surveys. Most children (128 boys) were from two-parent households, with an even SEIFA spread (based on Australian Bureau Statistics 2006 index for areas ranging from $1=$ most disadvantaged to $10=$ most advantaged; www.abs.gov.au), and from an Anglo-Saxon cultural background with normal dietary requirements. Many parents had a university degree and average-to-overweight BMI (Table 1).

Daily average of combined fruit/vegetable consumption (servings/d) was reported for 261 children (mean 5.9, SD 2-8); non-core food consumption (servings/week) was reported and calculated as a daily average for 255 children (mean $1 \cdot 8$, sD $1 \cdot 0$ ). Complete GNKQ were received from 269 parents (mean score $73 \cdot 3$, sD $13 \cdot 1$ ). As expected, higher GNK scores were associated with higher fruit/vegetable consumption $(r=0 \cdot 16, P<0 \cdot 01)$ and lower non-core food consumption $(r=-0 \cdot 18, P<0 \cdot 01)$ by children.

\section{Preparation for data analysis}

Of potential confounders (demographic and family environment variables), fruit/vegetable consumption was

Table 1 Summary of demographics and nutrition knowledge scores for parents and their 2-5-year-old children

\begin{tabular}{|c|c|c|c|c|c|c|c|}
\hline & \multicolumn{4}{|c|}{ Parents (n 269) } & & & \\
\hline & \multicolumn{2}{|c|}{ Parent 1} & \multicolumn{2}{|c|}{ Parent 2} & & \multicolumn{2}{|c|}{ Children (n 269) } \\
\hline & Mean & SD & Mean & SD & & Mean & SD \\
\hline Age (years) & $34 \cdot 9$ & $5 \cdot 5$ & $37 \cdot 6$ & $6 \cdot 1$ & Age (years) & $3 \cdot 6$ & 0.9 \\
\hline BMI $\left(\mathrm{kg} / \mathrm{m}^{2}\right)$ & $25 \cdot 6$ & $5 \cdot 6$ & $26 \cdot 6$ & $4 \cdot 2$ & BMI Z-score & $0 \cdot 1$ & $1 \cdot 8$ \\
\hline Gender & & & & & \multicolumn{3}{|l|}{ Gender } \\
\hline Male $(n)$ & \multicolumn{2}{|c|}{29} & & & Male $(n)$ & \multicolumn{2}{|c|}{128} \\
\hline Female $(n)$ & \multicolumn{2}{|c|}{239} & & & Female $(n)$ & \multicolumn{2}{|c|}{141} \\
\hline Number of children & $2 \cdot 2$ & 0.9 & & & Attended child care (\%) & \multicolumn{2}{|c|}{$72 \cdot 6$} \\
\hline Two-parent family status (\%) & \multicolumn{2}{|c|}{91} & & & Breast-feeding (\%) & \multicolumn{2}{|c|}{$86 \cdot 7$} \\
\hline Socio-economic status (\%) & \multicolumn{2}{|c|}{91} & & & Special dietary needs (\%) & \multicolumn{2}{|c|}{$5 \cdot 9$} \\
\hline Very low or low $(1,2,3)$ & \multicolumn{2}{|c|}{$20 \cdot 7$} & & & Television viewing (\%) & & \\
\hline Middle $(4,5,6,7)$ & \multicolumn{2}{|c|}{$49 \cdot 2$} & & & $2 \mathrm{~h} / \mathrm{d}$ or less & \multicolumn{2}{|c|}{$71 \cdot 6$} \\
\hline Very high or high $(8,9,10)$ & \multicolumn{2}{|c|}{$30 \cdot 1$} & & & Family dine together (\%) & & \\
\hline Combined annual family income (\$AU) & & & & & $\geq 5$ times/week & \multicolumn{2}{|c|}{$68 \cdot 2$} \\
\hline$\leq 13000$ & \multicolumn{2}{|c|}{$9 \cdot 7$} & & & Takeaway meals (\%) & & \\
\hline 13001 to 50000 & & & & $\leq 1$ time/week & \multicolumn{2}{|c|}{$90 \cdot 7$} \\
\hline 50001 to 100000 & \multicolumn{2}{|c|}{$46 \cdot 7$} & & & Cultural background (\%) & \\
\hline 100001 to 150000 & \multicolumn{2}{|c|}{$19 \cdot 7$} & & & Australian & & \\
\hline$\geq 150001$ & \multicolumn{2}{|c|}{$9 \cdot 0$} & & & Indigenous & \multicolumn{2}{|c|}{0.8} \\
\hline Weekly hours of employment & $19 \cdot 9$ & $17 \cdot 2$ & $37 \cdot 2$ & $15 \cdot 3$ & Other & \multirow{2}{*}{\multicolumn{2}{|c|}{$36 \cdot 0$}} \\
\hline Type of employment (\%) & & & & & & & \\
\hline Full time & \multicolumn{2}{|c|}{$18 \cdot 0$} & \multicolumn{2}{|c|}{$77 \cdot 7$} & & & \\
\hline Part time or casual & & & & & & & \\
\hline Home duties & & & & & & & \\
\hline Education level (\%) & & & & & & & \\
\hline High school & & & & & & & \\
\hline Trade or apprenticeship & & & & & & & \\
\hline Certificate or Diploma & & & & & & & \\
\hline University degree or higher & & & & & & & \\
\hline Parent 1 nutrition knowledge & $73 \cdot 3$ & $13 \cdot 1$ & & & & & \\
\hline
\end{tabular}

Data are presented as mean and standard deviation or percentage as indicated. Parent 1 denotes the parent who completed the questionnaire, parent 2 is the other parent in the family. 
significantly associated with eating dinner as a family $(r=0 \cdot 21, P=0 \cdot 001)$ and non-core food with child age $(r=0 \cdot 16, P=0 \cdot 012)$, takeaway food $(r=0 \cdot 20, P=0 \cdot 001)$ and television viewing $(r=0 \cdot 30, P<0 \cdot 001)$.

There were some missing data which would have eliminated sixty participants from the analysis. The pattern of missingness was tested using Little's MCAR test $\left(\chi^{2}=327 \cdot 55, \mathrm{df}=315, P=0 \cdot 301\right)$. The non-significance indicates that the data are missing completely at random. As a result multiple imputation was employed; twenty data sets were imputed using STATA version 12 and the results were combined using Rubin guidelines ${ }^{(61)}$.

\section{Regression and mediation analyses}

Collinearity was tested by computation of the variance inflation factors among the predictors, with no sensitivity recorded. Regression analysis results are shown in Table 2. In the final models, predictors of higher fruit/vegetable consumption were families dining together and higher authoritative parenting as well as lower restriction and lower over-reactive parenting, with the model explaining $19 \%$ of the variance. Further, laxness ( $P=0 \cdot 083 ; 95 \%$ CI $-0.635,0.045)$ approached statistical significance in the final model. GNK was not a significant predictor. Conversely, non-core food consumption was predicted by higher lax and over-reactive parenting, along with child age, television viewing and eating takeaway food more frequently, with $28 \%$ of the variance explained by the model. GNK had a small, significant effect $(P=0 \cdot 043)$ and was a mediator for authoritative parenting and non-core food (effect $=-0 \cdot 0052$, sE $=0 \cdot 0031 ; 95 \%$ CI $-0 \cdot 0122,-0 \cdot 0001)$.

\section{Discussion}

We hypothesised that parents' GNK would mediate relationships between parenting styles and feeding practices and child diet, controlling for demographic and family environment variables. In our models, over-reactive parenting and restrictive feeding practices were associated with lower fruit/vegetable consumption, and authoritative parenting and dining together as a family were associated with higher fruit/vegetable consumption; however, parental GNK was not a significant predictor or mediator. Over-reactive parenting and lax parenting were associated with higher non-core food consumption as well as with number of hours of television viewed by the child, takeaway food consumption and child's age. Parental GNK had a small effect on non-core food consumption and mediated the effect of authoritative parenting on non-core food consumption. The other parenting variables were independent predictors.

As highlighted in the introduction to the present paper, only four cross-sectional studies have previously evaluated the role of GNK with parents of children in this age range, none of which reported any direct associations

Table 2 Regression coefficients in final models for predictor variables (parenting styles and feeding practices) of child diet (fruit/vegetables and non-core foods), with demographic and family environment variables as covariates and general nutrition knowledge as mediator

\begin{tabular}{|c|c|c|c|c|c|c|}
\hline Predictor & $R^{2}$ & $F$ & Coefficient & SE & $t$ & $P$ \\
\hline \multicolumn{7}{|c|}{ Dependent variable: Fruit and vegetable consumption } \\
\hline Model summary & $0 \cdot 190$ & $5 \cdot 486$ & & & & 0.000 \\
\hline Permissive parenting & & & $-0 \cdot 307$ & 0.266 & $-1 \cdot 154$ & $0 \cdot 250$ \\
\hline Authoritarian parenting & & & $0 \cdot 102$ & 0.221 & 0.463 & 0.644 \\
\hline Authoritative parenting & & & 0.663 & 0.309 & $2 \cdot 144$ & 0.033 \\
\hline Laxness & & & $-0 \cdot 295$ & $0 \cdot 170$ & $-1 \cdot 741$ & 0.083 \\
\hline Over-reactivity & & & -0.386 & $0 \cdot 168$ & $-2 \cdot 303$ & 0.022 \\
\hline Verbosity & & & $0 \cdot 182$ & 0.239 & $0 \cdot 762$ & 0.447 \\
\hline Monitoring & & & -0.237 & 0.476 & -0.498 & 0.619 \\
\hline Pressure to eat & & & $-0 \cdot 107$ & 0.309 & -0.345 & 0.731 \\
\hline Restriction & & & -0.545 & $0 \cdot 178$ & $-3 \cdot 057$ & 0.003 \\
\hline Dinner as a family & & & $1 \cdot 451$ & 0.544 & $2 \cdot 666$ & 0.008 \\
\hline GNK & & & $0 \cdot 126$ & 0.086 & $1 \cdot 468$ & $0 \cdot 143$ \\
\hline \multicolumn{7}{|c|}{ Dependent variable: Non-core food consumption } \\
\hline Model summary & $0 \cdot 276$ & $7 \cdot 466$ & & & & 0.000 \\
\hline Permissive parenting & & & -0.002 & 0.013 & $-0 \cdot 140$ & 0.889 \\
\hline Authoritarian parenting & & & -0.007 & 0.011 & -0.659 & 0.511 \\
\hline Authoritative parenting & & & 0.009 & 0.015 & 0.575 & 0.566 \\
\hline Laxness & & & 0.019 & 0.008 & $2 \cdot 293$ & 0.023 \\
\hline Over-reactivity & & & 0.026 & 0.008 & $3 \cdot 149$ & 0.002 \\
\hline Verbosity & & & -0.002 & 0.012 & $-0 \cdot 129$ & 0.897 \\
\hline Monitoring & & & 0.000 & 0.023 & 0.009 & 0.993 \\
\hline Pressure to eat & & & -0.014 & 0.015 & -0.932 & 0.353 \\
\hline Restriction & & & 0.014 & 0.009 & $1 \cdot 533$ & $0 \cdot 126$ \\
\hline No. hours of television viewed by child & & & 0.225 & 0.060 & $3 \cdot 747$ & 0.000 \\
\hline Takeaway food consumption & & & 0.208 & 0.088 & $2 \cdot 358$ & 0.019 \\
\hline Child's age & & & $0 \cdot 135$ & 0.058 & $2 \cdot 332$ & 0.021 \\
\hline GNK & & & -0.009 & 0.004 & $-2 \cdot 031$ & 0.043 \\
\hline
\end{tabular}

GNK, general nutrition knowledge (parent). 
with child diet. Earlier research found that meal planners' GNK mediated child fat consumption in the home environment; although results for total fat consumption failed to reach significance ${ }^{(43)}$. Another study, which included 2-5-year-olds and up to 17-year-olds, found that better quality of the child's diet was more likely when coupled with higher maternal knowledge of health and nutrition, particularly in children of pre-school age ${ }^{(62)}$. However, our results suggest that these findings need to be placed in the context of parenting styles and practices.

The role of lax parenting in poorer dietary outcomes is supportive of previous research with permissive/indulgent parenting ${ }^{(30,33,41,42,63)}$ or lack of covert control ${ }^{(32)}$. Much of the research on restrictive feeding practices has focused on parent concern about child overweight. Similarly, more recent research reported that maternal food restriction was in response to 2-4-year-old children's food responsiveness (eating in the absence of hunger), and this was mediated to some degree by parental concern about child overweight ${ }^{(64)}$. However, longitudinal analysis found that restriction did not predict changes in child eating behaviour ${ }^{(65)}$. All in all, research findings with restrictive feeding practices, along with our contradictory finding, are problematic, given that the seemingly opposite style of laxness, i.e. letting children do whatever they want, is also unrelated to healthy food consumption. Over-reactive parenting is associated with more aggressive and controlling practices, similar to authoritarian parenting. Therefore, taken as a whole, these results suggest that restriction in certain contexts, i.e. healthy boundaries in conjunction with positive, supportive and encouraging parenting (a function of authoritative parenting which was associated with higher fruit/vegetable consumption), may be necessary to assist children to make healthier food choices.

To our knowledge, the present study is the first one not only to investigate parenting styles and nutrition knowledge, but also to control for family environment variables with parents of pre-school children. Our results support the role of parenting in combination with broadspectrum influences within the family environment. Dining together as a family predicted increased fruit/ vegetable consumption, supporting previous research with older children showing similar outcomes ${ }^{(66-68)}$. More recent research with pre-school children has found positive associations with 'family mealtime' variables such as eating the same food as their parents and meals and sauces prepared from scratch ${ }^{(69)}$. Conversely, eating takeaway food was associated with higher non-core food consumption, as was more hours of television viewing by the child. The relationship between television viewing and increased non-core food consumption has also been found with older children ${ }^{(70)}$. Notably, there is a higher prevalence of confectionery (three times more likely) and fast food (twice as likely) advertising broadcast on Australian television during the scheduling of children's programmes than during adult viewing ${ }^{(71)}$. The concurrent and slight mediating influence of GNK on non-core food consumption points to the importance of targeting nutrition knowledge along with positive parenting practices and family environment - although our results suggest that nutrition knowledge on its own will not be sufficient to help parents improve their children's diets.

Although much research has investigated parenting and family functioning ${ }^{(72)}$ in relation to child diet, not many studies appear to have used the $\mathrm{PS}^{(53)}$ and yet this measure yielded notable results; perhaps tapping into other aspects of the classic parenting styles with regard to their influence on child diet. Inconsistent findings that have been highlighted in the present paper may be attributed to the use of tools that do not measure important aspects of parenting or feeding practices that impact on child diet. In fact there are a few tools that measure parent feeding practices ${ }^{(25,39,52,73,74)}$, with some researchers $^{(39)}$ asserting that earlier measures ${ }^{(52,73,74)}$ were limited to measuring mostly a subset of feeding practices leading to the subsequent development of a broader tool ${ }^{(39)}$. The Caregivers Feeding Style Questionnaire (CFSQ) is a thirty-eight-item questionnaire that included relevant items from both the $\mathrm{CFQ}^{(52)}$ and the Parenting Dimensions Inventory (PDI) ${ }^{(75)}$ and included two new measures of parent feeding. Differences on these two dimensions of demandingness and responsiveness resulted in four feeding styles: authoritative, authoritarian, indulgent and uninvolved (aligned with the parenting styles identified by Maccoby and Martin ${ }^{(76)}$ ). It should be noted that Maccoby and Martin considered levels of demandingness and responsiveness in relation to general parenting, whereby demandingness refers to the extent parents show control, maturity, demands and supervision while responsiveness refers to the extent parents show warmth, acceptance and involvement ${ }^{(76)}$. Hughes et al. operationalised demandingness and responsiveness in the feeding domain whereby 'demandingness refers to how much the parent encourages eating and responsiveness refers to how the parents encourage eating, ${ }^{,(39)}$.

In addition, Carnell and Wardle looked at multiple measures of parental feeding by comparing the scales of the CFQ, Preschooler Feeding Questionnaire (PFQ) and Parental Feeding Style Questionnaire (PFSQ) $)^{(52,73,74)}$ in relation to child adiposity ${ }^{(24)}$. Results indicate that increased encouragement and pressure to eat were more consistently associated with lower child weight whereas no associations were found with other parental feeding styles. However, Musher-Eizenman and Holub ${ }^{(25)}$ suggest that the emphasis on controlling practices (pressure and/or restriction) as presented by Hughes et al. ${ }^{(39,77)}$ and Carnell and Wardle ${ }^{(24)}$ may have prevented exploration of other important constructs and propose that restriction should be a separate construct. Musher-Eizenman and Holub also highlight the importance of parental modelling of healthy 
foods and food exposure as effective feeding practices, yet note that these constructs are not included in self-reported measures of parental feeding ${ }^{(78-80)}$. These researchers acknowledge the work conducted with parent GNK on food choices ${ }^{(81)}$; however, they comment that current measures do not examine the extent to which parents try to teach children about nutrition.

To develop their tool these researchers ${ }^{(25)}$ included relevant items from the $\mathrm{PFQ}^{(82)}$ and the $\mathrm{CFQ}^{(52)}$. Additional items were adapted from the Dutch Eating Behavior Questionnaire - Restrained Eating Scale ${ }^{(83)}$, the authors' own previous work ${ }^{(84)}$ and items that emerged from the literature and/or as suggested by parents throughout the research. This information then informed the development of the 'restriction for health', 'restriction for weight' and 'food to regulate a child's emotions' scales, resulting in a forty-nine-item (twelve subscales) valid and reliable Comprehensive Feeding Practices Questionnaire (CFPQ) which has, since the commencement of the present research, been validated with an Australian population ${ }^{(85)}$. Notably one of the subscales is 'teaching about nutrition'; however, it contains only three items and the researchers themselves note that internal consistency of items on these scales was low ${ }^{(86)}$. Therefore, this questionnaire could be further developed by the inclusion of a broader nutrition component as our study indicates that nutrition knowledge may have an independent influence in conjunction with, and as a small mediator of, parental influences on child diet. These measures would also benefit from more careful distinction of restrictive feeding practices associated with healthy boundaries and positive parenting as opposed to those associated with inflammatory, controlling parenting styles.

It should be noted that participation in the present study was voluntary and participants may have had a higher interest in healthy child diet, resulting in selection bias. We minimised this possibility via stratified SEIFA sampling and provision of movie passes for completed questionnaires to encourage participation by lowerincome families. Additionally, the study is cross-sectional and does not necessarily imply causation or eliminate all potential confounders. Finally, the study used a selfreport questionnaire and is inevitably open to desirability bias, where a parent might report what he/she knows is desirable behaviour and/or under-report behaviour due to personal/cultural beliefs or perceptions.

However, the strengths are the adequate sample size, relatively even distribution of responses across SEIFA areas, inclusion of family environment variables as well as nutrition knowledge and parenting styles, and use of validated questionnaires with well distributed data. Future research should pay attention to the development of more comprehensive tools investigating parenting styles and the family environment/functioning specific to feeding practices, with careful attention to operationalisation of restrictive feeding practices $v$. laxness/permissiveness, and investigate these influences longitudinally to further aid in intervention and policy design. A greater understanding of these areas will provide a platform for intervention design and behaviour change in the promotion of healthy habit formation in the early years. Future parenting interventions may benefit from encouraging parents to promote positive and supportive feeding practices in line with authoritative parenting, including positive, warm communication and healthy boundary setting around food and television viewing in combination with healthy nutrition education and role modelling.

\section{Acknowledgements}

Sources of funding: J. Peters is supported by a $\mathrm{PhD}$ scholarship from the University of South Australia. N.P. is supported by National Health and Medical Research Council Program Grant funding (\# 320860 and 631947). Conflicts of interest: The authors declare no conflicts of interest. Authors' contributions: J. Peters, N.P. and J.D. were involved in the conception of the research. The study data were collected by J. Peters. J. Petkov statistically analysed data with the assistance of all other authors. J. Peters and N.P. prepared the manuscript and all authors contributed to the editing of the manuscript.

\section{References}

1. Commonwealth Scientific Industrial Research Organisation (CSIRO) Preventative Health National Research Flagship \& the University of South Australia (2007) 2007 Australian National Children's Nutrition and Physical Activity Survey: Main Findings. Canberra: Commonwealth of Australia.

2. Magarey A \& Daniels L (2001) Comparison of Australian and US data on overweight and obesity in children and adolescents. Med J Aust 175, 500-501.

3. Magarey AM, Daniels LA \& Boulton TJC (2001) Prevalence of overweight and obesity in Australian children and adolescents: reassessment of 1985 and 1995 data against new standard international definitions. Med J Aust 174, 561-564.

4. Serdula MK, Ivery D, Coates RJ et al. (1993) Do obese children become obese adults? A review of the literature. Prev Med 22, 167-177.

5. Whitaker RC, Wright JA, Pepe MS et al. (1997) Predicting obesity in young adulthood from childhood and parental obesity. $N$ Engl J Med 337, 869-873.

6. Magarey AM, Daniels LA, Boulton TJ et al. (2003) Predicting obesity in early adulthood from childhood and parental obesity. Int J Obes Relat Metab Disord 27, 505-513.

7. Edmunds L, Walters E \& Elliott E (2001) Evidence based management of childhood obesity. BMJ 323, 916-919.

8. Campbell KJ, Crawford DA \& Ball K (2006) Family food environment and dietary behaviors likely to promote fatness in 5-6 year-old children. Int J Obes (Lond) 30, $1272-1280$.

9. Peters J, Sinn N, Campbell K et al. (2012) Parental influences on the diets of 2-5-year-old children: systematic review of interventions. Early Child Dev Care 182, 837-857.

10. Peters J, Parletta N, Campbell K et al. (2012) Parental influences on the diets of 2-5 year old children: systematic review of qualitative research. J Early Child Res (In the Press). 
11. Drucker RR, Hammer LD, Agras Ws et al. (1999) Can mothers influence their child's eating behavior? J Dev Behav Pediatr 20, 88-92.

12. Fisher JO \& Birch LL (1999) Restricting access to foods and children's eating. Appetite 32, 405-419.

13. Fisher JO \& Birch LL (1999) Restricting access to a palatable food affects children's behavioural response, food selection and intake. Am J Clin Nutr 69, 1264-1272.

14. Birch LL \& Fisher JO (2000) Mothers' child-feeding practices influence daughters' eating and weight. $A m \mathrm{~J}$ Clin Nutr 71, 1054-1061.

15. Birch LL, Fisher JO \& Davison KK (2003) Learning to overeat: maternal use of restrictive feeding practices promotes girls' eating in the absence of hunger. Am J Clin Nutr 78, 215-220.

16. Faith MS, Berkowitz RI, Stallings VA et al. (2004) Parental feeding attitudes and styles and child body mass index: prospective analysis of a gene-environment interaction. Pediatrics 114, E429-E436.

17. Liem DG, Mars M \& De Graaf C (2004) Sweet preferences and sugar consumption of 4- and 5-year-old children: role of parents. Appetite 43, 235-245.

18. Arredondo EM, Elder JP, Ayala GX et al. (2006) Is parenting style related to children's healthy eating and physical activity in Latino families? Health Educ Res 21, 862-871.

19. Faith MS, Dennison BA, Edmunds LS et al. (2006) Fruit juice intake predicts increased adiposity gain in children from low-income families: weight status-by-environment interaction. Pediatrics 118, 2066-2075.

20. Jiang J, Rosenqvist U, Wang H et al. (2006) Risk factors for overweight in 2- to 6-year-old children in Beijing, China. Int J Pediatr Obes 1, 103-108.

21. Johannsen DL, Johannsen NM \& Specker BL (2006) Influence of parents' eating behaviors and child feeding practices on children's weight stuatus. Obesity (Silver Spring) 14, 431-439.

22. Montgomery C, Jackson DM, Kelly LA et al. (2006) Parental feeding style, energy intake and weight status in young Scottish children. BrJ Nutr 96, 1149-1153.

23. Powers SW, Chamberlin LA, van Schaick KB et al. (2006) Maternal feeding strategies, child eating behaviors, and child BMI in low-income African-American preschoolers. Obesity (Silver Spring) 14, 2026-2033.

24. Carnell S \& Wardle J (2007) Associations between multiple measures of parental feeding and children's adiposity in United Kingdom preschoolers. Obesity (Silver Spring) 15, 137-144.

25. Musher-Eizenman D \& Holub S (2007) Comprehensive feeding practices questionnaire: validation of a new measure of parental feeding practices. J Pediatr Psychol 32, 960-972.

26. Kroller K \& Warschburger P (2008) Associations between maternal feeding style and food intake of children with a higher risk for overweight. Appetite 51, 166-172.

27. Spurrier NJ, Magarey AA, Golley R et al. (2008) Relationships between the home environment and physical activity and dietary patterns of preschool children: a cross-sectional study. Int J Behav Nutr Phys Act 5, 31.

28. Joyce JL \& Zimmer-Gembeck MJ (2009) Parent feeding restriction and child weight. The mediating role of child disinhibited eating and the moderating role of the parenting context. Appetite 52, 726-734.

29. Blisset J, Meyer C \& Haycraft E (2006) Maternal and paternal controlling feeding practices with male and female children. Appetite 47, 212-219.

30. Olvera N \& Power TG (2010) Parenting styles and obesity in Mexican American children: a longitudinal study. J Pediatr Psychol 35, 243-249.

31. Fisher JO \& Birch LL (2000) Parents' restrictive feeding practices are associated with young girls' negative selfevaluation of eating. J Am Diet Assoc 100, 1341-1346.
32. Brown K, Ogden J, Vogele C et al. (2008) The role of parental control practices in explaining children's diet and BMI. Appetite 50, 252-259.

33. Wake M, Nicholson J, Hardy P et al. (2007) Preschooler obesity and parenting styles of mothers and fathers: Australian national population study. Pediatrics 120, $1520-1527$.

34. Blissett J \& Haycraft E (2008) Are parenting style and controlling feeding practices related? Appetite 50, 477-485.

35. Haycraft EL \& Blissett JM (2008) Maternal and paternal controlling feeding practices: reliability and relationships with BMI. Obesity (Silver Spring) 16, 1552-1558.

36. Gubbels JS, Kremers SPJ, Stafleu A et al. (2009) Diet-related restrictive parenting practices. Impact on dietary intake of 2 -year-old children and interactions with child characteristics. Appetite 52, 423-429.

37. Keller KL, Pietrobelli A, Johnson SL et al. (2006) Maternal restriction of children's eating and encouragements to eat as the 'non-shared environment': a pilot study using the Child Feeding Questionnaire. Int J Obes (Lond) 30, 1670-1675.

38. Corsini N, Danthiir V, Kettler L et al. (2008) Factor structure and psychometric properties of the Child Feeding Questionnaire in Australian preschool children. Appetite 51, 474-481.

39. Hughes S, Power T, Fisher J et al. (2005) Revisiting a neglected construct: parenting styles in a child-feeding context. Appetite 44, 83-92.

40. Patrick H, Nicklas TA, Hughes SO et al. (2005) The benefits of authoritative feeding style: caregiver feeding styles and children's food consumption patterns. Appetite 44, 243-249.

41. Rhee K, Lumeng J, Appulgliese D et al. (2006) Parenting styles and overweight status in first grade. Pediatrics 117, 2047-2054.

42. Hoerr S, Hughes S, Fisher J et al. (2009) Associations among parental feeding styles and children's food intake in families with limited incomes. Int J Behav Nutr Phys Act $\mathbf{6}$, 55.

43. Colavito EA, Guthrie JF, Hertzler AA et al. (1996) Relationship of diet-health attitudes and nutrition knowledge of household meal planners to the fat and fiber intakes of meal planners and preschoolers. J Nutr Educ 28, 321-328.

44. Etelson D, Brand DA, Patrick PA et al. (2003) Childhood obesity: do parents recognize this health risk? Obesity (Silver Spring) 11, 1362-1368.

45. Stolley MR, Fitzgibbon ML, Dyer A et al. (2003) Hip-Hop to Health Jr., an obesity prevention program for minority preschool children: baseline characteristics of participants. Prev Med 36, 320-329.

46. Hudson C, Craig Stotts R, Pruett J et al. (2005) Parents' dietrelated attitudes and knowledge, family fast food dollars spent, and the relation to BMI and fruit and vegetable intake of their preschool children. South Online J Nurs Res 6, 1-23.

47. MacCallum RC, Browne MW \& Sugawara HM (1996) Power analysis and determination of sample size for covariance structure modeling. Psychol Methods 1, 130-149.

48. Goodman E, Hinden BR \& Khandelwal S (2000) Accuracy of teen and parental reports of obesity and body mass index. Pediatrics 106, 52-58.

49. Variyam JN (2001) Overweight children: is parental nutrition knowledge a factor? Food Rev 24, 18.

50. Magarey A, Golley R, Spurrier N et al. (2009) Reliability and validity of the Children's Dietary Questionnaire: a new tool to measure children's dietary patterns. Int J Pediatric Obes 4, 257-265.

51. Byers T, Treiber F, Gunter E et al. (1993) The accuracy of parental reports of their children's intake of fruits and vegetables: validation of a food frequency questionnaire with serum levels of carotenoids and vitamins $\mathrm{C}, \mathrm{A}$, and $\mathrm{E}$. Epidemiology 4, 350-355. 
52. Birch LL, Fisher JO, Grimm-Thomas K et al. (2001) Confirmatory factor analysis of the Child Feeding Questionnaire: a measure of parental attitudes, beliefs and practices about child feeding and obesity proneness. Appetite 36, 201-210.

53. Arnold DS, O'Leary SG, Wolff LS et al. (1993) The parenting scale: a measure of dysfuncitonal parenting in discipline situations. Psychol Assess 5, 137-144.

54. Irvine AB, Biglan A, Smolkowski K et al. (1999) The value of the Parenting Scale for measuring the discipline practices of parents of middle school children. Behav Res Ther 37, 127-142.

55. Harvey E, Danforth JS, Ulaszek WR et al. (2001) Validity of the parenting scale for parents of children with attentiondeficit/hyperactivity disorder. Behav Res Ther 39, 731-743.

56. Reitman D, Rhode P, Hupp S et al. (2002) Development and validation of the Parental Authority Questionnaire Revised. J Psychopathol Behav Assess 24, 119-127.

57. Buri JR (1991) Parental authority questionnaire. J Pers Assess 57, 110-119.

58. Hendrie G, Cox D \& Coveney J (2008) Validation of the General Nutrition Knowledge Questionnaire in an Australian community sample. Nutr Diet 65, 72-77.

59. Parmenter K \& Wardle J (1999) Development of a general nutrition knowledge questionnaire for adults. Eur J Clin Nutr 53, 298-308.

60. Efron B (1981) Nonparametric estimates of standard error: the jackknife, the bootstrap and other methods. Biometrika 68, 589-599.

61. Schafer J (1997) Analysis of Incomplete Multivariate Data. London: Chapman \& Hall.

62. Blaylock J, Variyam JN \& Lin B (1999) Maternal Nutrition Knowledge and Children's Diet Quality and Nutrient Intakes. Food Assistance and Nutrition Research Report no. FANRR1. Washington, DC: US Department of Agriculture, Economic Research Service, Food and Rural Economics Division.

63. Kasemsup R \& Reicks M (2006) The relationship between maternal child-feeding practices and overweight in Hmong preschool children. Ethn Dis 16, 187-193.

64. Gregory JE, Paxton SJ \& Brozovic AM (2010) Pressure to eat and restriction are associated with child eating behaviours and maternal concern about child weight, but not child body mass index, in 2- to 4-year-old children. Appetite 54, 550-556.

65. Gregory J, Paxton S \& Brozovic A (2010) Maternal feeding practices, child eating behaviour and body mass index in preschool-aged children: a prospective analysis. Int J Behav Nutr Phys Act 7, 55.

66. Gillman MW, Rifas-Shiman SL, Frazier AL et al. (2000) Family dinner and diet quality among older children and adolescents. Arch Fam Med 9, 235-240.

67. Neumark-Sztainer D, Hannan PJ, Story M et al. (2003) Family meal patterns: associations with sociodemographic characteristics and improved dietary intake among adolescents. J Am Diet Assoc 103, 317-322.

68. Videon TM \& Manning CK (2003) Influences on adolescent eating patterns: the importance of family meals. J Adolesc Health 32, 365-373.

69. Sweetman C, McGowan L, Croker H et al. (2011) Characteristics of family mealtimes affecting children's vegetable consumption and liking. J Am Diet Assoc 111, 269-273.
70. Salmon J, Campbell K \& Crawford D (2006) Television viewing habits associated with obesity risk factors: a survey of Melbourne schoolchildren. Med J Aust 184, 64-67.

71. Neville L, Thomas M \& Bauman A (2005) Food advertising on Australian television: the extent of children's exposure. Health Promot Int 20, 105-112.

72. Rhee K (2008) Childhood overwight and the relationship between parent behaviors, parenting style \& family functioning. Ann Am Acad Pol Soc Sci 615, 12-37.

73. Baughcum AE, Powers SW, Johnson SB et al. (2001) Maternal feeding practices and beliefs and their relationships to overweight in early childhood. J Dev Behav Pediatr 22, 391-408.

74. Wardle J, Sanderson S, Guthrie CA et al. (2002) Parental feeding style and the inter-generational transmission of obesity risk. Obes Res 10, 453-462.

75. Hardy DF, Power TG \& Jaedicke S (1993) Examining the relation of parenting to children's coping with everyday stress. Child Dev 64, 1829-1841.

76. Maccoby E, Martin J (1983) Socialization in the context of the family: parent-child interaction. In Handbook of Child Psychology, pp. 1-102 [P Mussen, editor]. New York: John Wiley \& Sons.

77. Hughes SO, Anderson CB, Power TG et al. (2006) Measuring feeding in low-income African-American and Hispanic parents. Appetite 46, 215-223.

78. Hendy HM \& Raudenbush B (2000) Effectiveness of teacher modeling to encourage food acceptance in preschool children. Appetite 34, 61-76.

79. Lee Y \& Birch L (2002) Diet quality, nutrient intake, weight status, and feeding environments of girls meeting or exceeding the American Academy of Pediatrics recommendations for total dietary fat. Minerva Pediatr 54, 179-186.

80. Wardle J, Cooke LJ, Gibson L et al. (2003) Increasing children's acceptance of vegetables: a randomized trial of parent-led exposure. Appetite 40, 155-162.

81. Gibson E, Wardle J \& Watts C (1998) Fruit and vegetable consumption, nutritional knowledge and beliefs in mothers and children. Appetite 31, 205-228.

82. Baughcum AE, Burklow KA, Deeks CM et al. (1998) Maternal feeding practices and childhood obesity: a focus group study of low-income mothers. Arch Pediatr Adolesc Med 152, 1010-1014.

83. van Strien T, Frijters JER, Bergers GPA et al. (1986) The Dutch Eating Behavior Questionnaire (DEBQ) for assessment of restrained, emotional and external eating behavior. Int J Eat Disord 5, 747-755.

84. Musher-Eizenman D, Holub S (2006) Children's eating in the absence of hunger: the role of restrictive feeding practices. In Childhood Obesity and Health Research, pp. 135-156 [R Flamenbaum, editor]. New York: Nova Science Publishers.

85. Kiernan M (2010) Construct validation of the Comprehensive Feeding Practices Questionnaire (CFPQ) in an Australian sample. Presented at ACSPRI Social Science Methodology Conference 2010, Sydney, Australia, 1-3 December 2010.

86. Musher-Eizenman DR, de Lauzon-Guillain B, Holub SC et al. (2009) Child and parent characteristics related to parental feeding practices. a cross-cultural examination in the US and France. Appetite 52, 89-95. 